\title{
Monitoring of non-communicable diseases such as hypertension in South Africa: Challenges for the post-2015 global development agenda
} \author{
N van Schaik, ${ }^{1} \mathrm{MB}$ ChB; D Bradshaw, ${ }^{2}$ DPhil (Oxon) \\ ${ }^{1}$ Health Systems Trust, Durban, South Africa \\ ${ }^{2}$ Burden of Disease Research Unit, Medical Research Council, Cape Town, South Africa \\ ${ }^{3}$ Biostatistics Unit, Medical Research Council, Cape Town, South Africa
}

C Day, ${ }^{1}$ BSc Pharm, MMedSci; P Groenewald, ${ }^{2} \mathrm{MB}$ ChB, MPH; R Laubscher, ${ }^{3}$ BComm; S Chaudhry, ${ }^{1}$ BSc MPH;

Corresponding author: Candy Day (candy.day@hst.org.za)

\begin{abstract}
Background. Examining the non-communicable disease (NCD) profile for South Africa (SA) is crucial when developing health interventions that aim to reduce the burden of NCDs.

Objective. To review NCD indicators in national data sources in order to describe the burden of NCDs in SA, using hypertension as an example Methods. Age, gender, district of death and underlying cause of death data were obtained for 2008 and 2009 mortality unit records from Statistics SA and adjusted using STATA 11. Data for raised blood pressure were obtained from four national household surveys: the South African Demographic and Health Survey 1998, the Study on Global Ageing and Adult Health 2007, and the National Income Dynamics Study 2008 and 2010.

Results. The proportion of years of life lost due to NCDs was highest in the metros and least-deprived districts, with all metros (especially Mangaung) showing high age-standardised mortality rates for ischaemic heart disease, cerebrovascular disease and hypertensive disease. The prevalence of hypertension has increased since 1998. National household surveys showed a measured hypertension prevalence of over $40 \%$ in adults aged $\geq 25$ years in 2010 . Treatment coverage was $35.7 \%$. Only $36.4 \%$ of hypertensive cases (on treatment) were controlled. Conclusion. Further work is needed if NCD monitoring is to be enhanced. Priority targets for NCDs must be integrated into national health planning processes. Surveillance requires integration into national health information systems. Within primary healthcare, a larger focus on integrated chronic care is essential.

S Afr Med J 2014;104(9):680-687. DOI:10.7196/SAMJ.7868
\end{abstract}

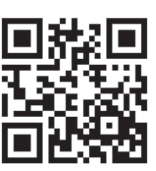

The idea of universal health coverage (UHC) as a goal of health policy development has gained wide acceptance at both national and global levels since the publication of the World Health Report 2010. ${ }^{[1]}$ UHC is now also being seen as a critical component of sustainable development and as such has been proposed as one of the key goals of the post-2015 development agenda that it is envisaged will extend the development challenges posed by the Millennium Development Goals. ${ }^{[2]}$ Its aim is to ensure that all have access to needed healthcare of sufficient quality to be effective and that all have financial protection from the costs associated with using such health services. Reducing non-communicable diseases (NCDs) and their risk factors is one of the neglected priorities within this goal.

In March 2013, the World Health Assembly adopted the comprehensive global monitoring framework for $\mathrm{NCDs}^{[3]}$ and urged member states to develop national targets and indicators. In August 2013, the South African (SA) national Department of Health (DoH) released its Strategic Plan for the Prevention and Control of Noncommunicable Diseases 2013-17,[4] setting out national goals and targets. Table 1 shows these targets, together with those of the World Health Assembly. Such a strategy was crucial, given that estimates had predicted that the burden of disease relating to NCDs would continue to rise in SA if left unchecked. ${ }^{[5,6]}$

In order to identify health interventions that will focus on reducing the burden of NCDs, it is important to examine the burden of NCD profile for the country. This study aimed to do this by reviewing NCD indicators in national data sources in SA.

\section{Methods}

The burden of disease analysis was based on the unit records for 2008 and 2009 mortality data provided by Statistics SA. These included age, sex, district of death and underlying cause of death coded to the 10th revision of the International Statistical Classification of Diseases and Related Health Problems (ICD-10). STATA 11 was used to adjust the data, firstly by redistributing deaths of unknown ages proportionally by age and gender across each of the known causes of death. Causes of death used as pseudonyms for AIDS were combined with the HIV deaths. Deaths misclassified to ill-defined signs and symptoms and other 'garbage codes' (intermediate causes of death such as septicaemia; mechanisms of death such as cardiac arrest, which could be produced by a variety of different causes; partially specified causes such as cancer with unknown site of the disease; or risk factors such as hypertension) were proportionally redistributed to specified causes within each age and gender category. The ICD codes were aggregated according to the updated National Burden of Disease (NBD) list, which is a condensed list of conditions containing the most prevalent diseases across SA, including those of public health importance. The proportions of deaths and years of life lost (YLLs) due to the four broad cause groups were calculated for each of the 52 districts. YLLs are a measure of premature mortality based on the age at death and therefore highlight the causes of death that should be targeted for prevention. In line with the initial SA NBD study, the highest observed national life expectancy was selected as the standard against which YLLs are calculated. 
Data for raised blood pressure are presented from four national household surveys: the South African Demographic and Health Survey (SADHS) $1998,{ }^{[7]}$ the Study on Global Ageing and Adult Health (SAGE) 2007, ${ }^{[8]}$ and the National Income Dynamics Study (NiDS) $2008^{[9]}$ (wave 1) and 2010 ${ }^{[10]}$ (wave 2). (Note: The third wave of the NiDS has been released, together with updates to the previous two waves, since this analysis was completed.)

Individuals were classified as hypertensive if their average systolic blood pressure was $\geq 140 \mathrm{mmHg}$ or their diastolic blood pressure $\geq 90$ $\mathrm{mmHg}$, or if they used blood pressure medication. The data were checked for outlier values, which were excluded from the analysis.
Individuals without a valid blood pressure measurement who were not on blood pressure medication were omitted from the analysis. (A valid blood pressure measurement complies with the following set of rules: systolic 80 - $240 \mathrm{mmHg}$; diastolic 35 - $140 \mathrm{mmHg}$; systolic at least 15 units more than the corresponding diastolic; absolute difference between two systolic or diastolic measurements not more than 5 units.)

While the surveys had similar procedures for measuring hypertension, the sampling procedures were slightly different. Triangulation of multiple data sources was therefore undertaken to better describe the burden of disease and effective treatment coverage of hypertension.

Table 1. Non-communicable disease prevention and control goals and targets set by the World Health Assembly and the South African Strategic Plan for the Prevention and Control of Non-communicable Diseases

\section{WHO, 66th World Health Assembly - a set of voluntary global targets for the} prevention and control of NCDs: Global targets for 2025 and selected indicators

\section{Premature mortality from non-communicable disease}

Target: A 25\% relative reduction in overall mortality from cardiovascular diseases, cancer, diabetes, or chronic respiratory diseases

Behavioural risk factors

Target: At least a $10 \%$ relative reduction in the harmful use of alcohol, as appropriate, within the national context

Target: A $10 \%$ relative reduction in prevalence of insufficient physical activity Indicators:

Prevalence of insufficiently physically active adolescents defined as $<60$ minutes of moderate- to vigorous-intensity activity daily

Age-standardised prevalence of insufficiently physically active persons aged $\geq 18$ years (defined as $<150$ minutes of moderate-intensity activity per week, or equivalent)

Target: A 30\% relative reduction in mean population intake of salt/sodium

Target: A 30\% relative reduction in prevalence of current tobacco use in persons aged $\geq 15$ years

Biological risk factors

Target: A 25\% relative reduction in the prevalence of raised BP, or contain the prevalence of raised $\mathrm{BP}$ according to the national circumstances

Indicator: Age-standardised prevalence of raised $\mathrm{BP}$ among persons aged $\geq 18$ years (defined as systolic BP $\geq 140 \mathrm{mmHg}$ and/or diastolic BP $\geq 90 \mathrm{mmHg}$ )

Target: Halt the rise in diabetes and obesity

Indicators:

Prevalence of overweight and obesity in adolescents

Age-standardised prevalence of overweight and obesity in persons aged

$\geq 18$ years (defined as BMI $\geq 25$ for overweight and BMI $\geq 30$ for obesity)

National systems response

Target: At least $50 \%$ of eligible people receive drug therapy and counselling (including glycaemic control) to prevent heart attacks and strokes

Indicator: Proportion of eligible persons (defined as aged $\geq 40$ years with a 10 -year cardiovascular risk $\geq 30 \%$, including those with existing cardiovascular disease) receiving drug therapy and counselling (including glycaemic control) to prevent heart attacks and strokes

Target: An $80 \%$ availability of the affordable basic technologies and essential medicines, including generics, required to treat major non-communicable diseases in both public and private facilities
South African Strategic Plan for the Prevention and Control of Non-communicable Diseases: 2020 goals and targets

1. Reduce by at least $25 \%$ the relative premature mortality ( $<60$ years) from NCDs by 2020

2. Reduce by $20 \%$ tobacco use by 2020

3. Reduce by $20 \%$ the per capita consumption of alcohol by 2020

4. Reduce mean population intake of salt to $<5 \mathrm{~g}$ per day by 2020

5. Reduce by $10 \%$ the percentage of people who are obese and/or overweight by 2020

6. Reduce the prevalence of people with raised BP by $20 \%$ by 2020 (through lifestyle and medication)

7. Increase the prevalence of physical activity (defined as 150 minutes of moderate-intensity physical activity per week, or equivalent) by $10 \%$

8. Every woman with sexually transmitted diseases to be screened for cervical cancer every 5 years, otherwise every woman to have three screens in a lifetime (and as per policy for women who are HIV-positive)

9. Increase the percentage of people controlled for hypertension, diabetes and asthma by $30 \%$ by 2020 in sentinel sites

10. Increase the number of people screened and treated for mental disorders by $30 \%$ by 2030 [sic] 


\section{RESEARCH}

\section{Results}

The burden of disease analysis shows that NCDs have become the largest broad cause of YLLs in South Africa $32.0 \%$ of YLLs in 2009). The percentage of YLLs per district by broad cause group is shown in
Fig. 1, highlighting substantial differences in the burden due to NCDs relative to that caused by injuries, HIV, tuberculosis, communicable, maternal, perinatal and nutrition-related diseases. The percentage of YLLs due to NCDs tends to be highest in the metros and least-deprived districts. Individual causes of death due to NCDs feature strongly in the ten leading causes of mortality. All metros show high agestandardised mortality rates for ischaemic heart disease, cerebrovascular disease and

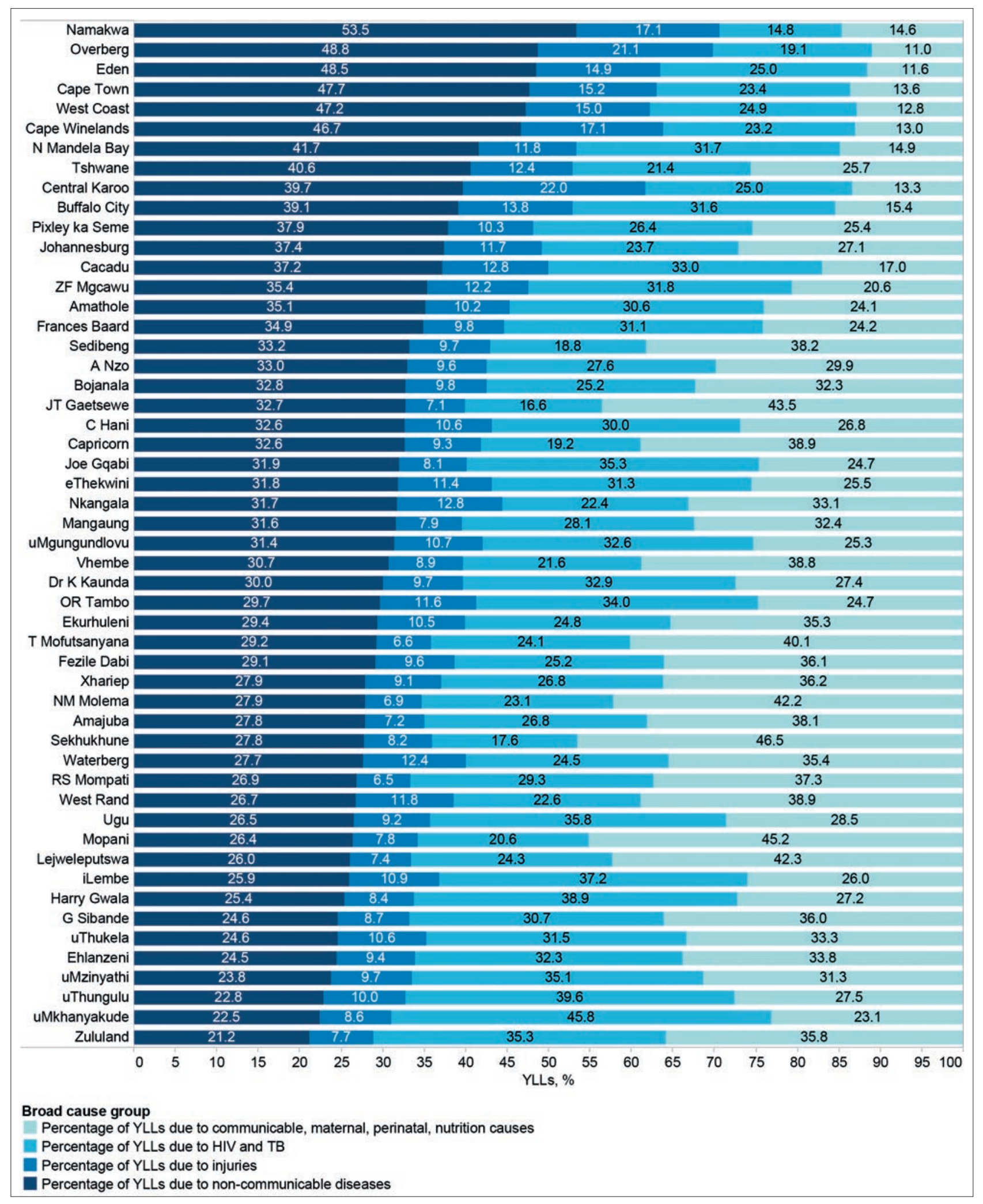

Fig. 1. Percentage of YLLs by broad cause group, by district, 2009. (YLLs = years of life lost; NCD = non-communicable disease; $T B=$ tuberculosis.) 
RESEARCH

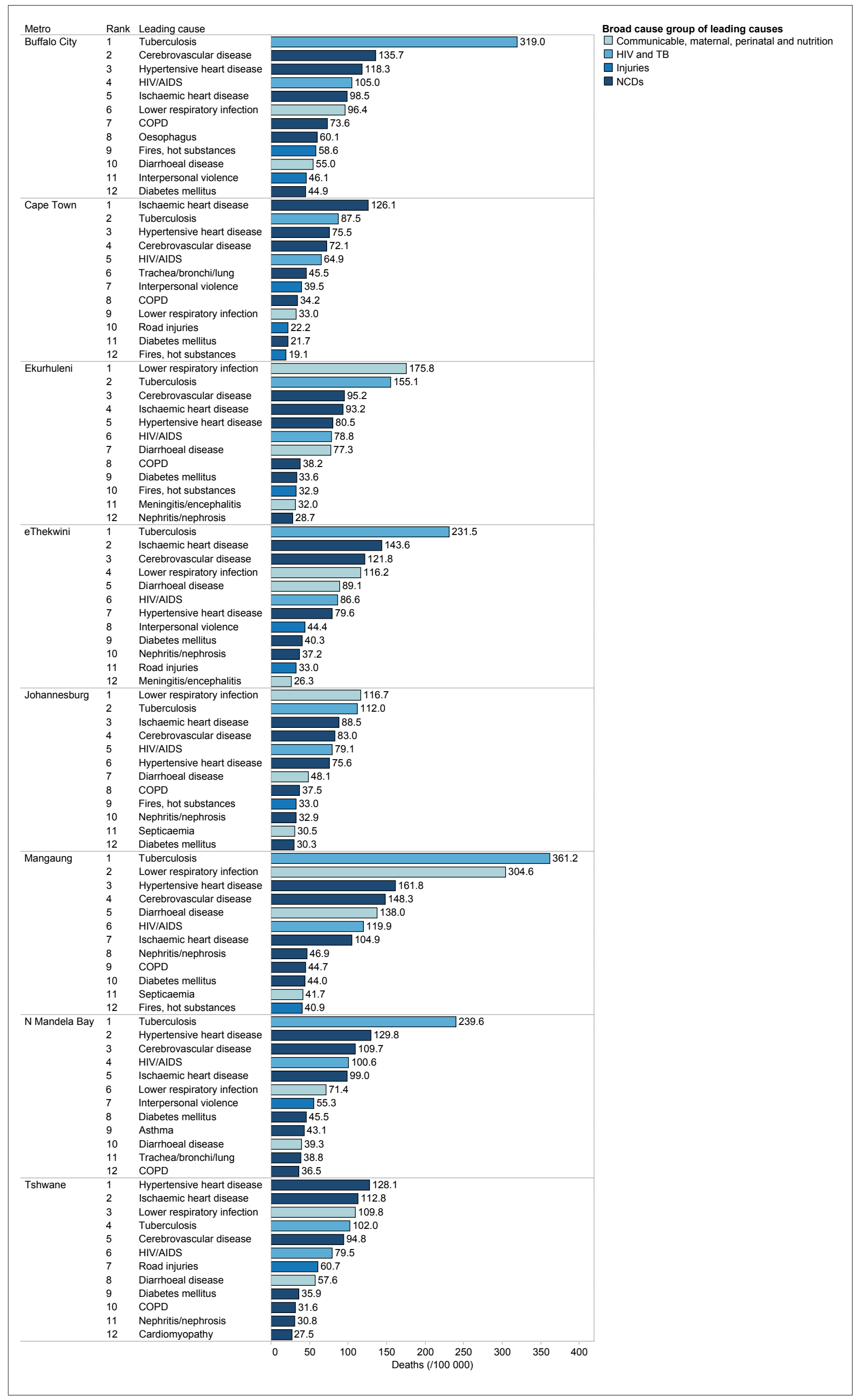

Fig. 2. Leading age-standardised mortality rates (deaths/100 000 population) by metro, highlighting NCD causes, 2009. (NCD = noncommunicable disease; $C O P D=$ chronic obstructive pulmonary disease; $T B=$ tuberculosis.) 


\section{RESEARCH}

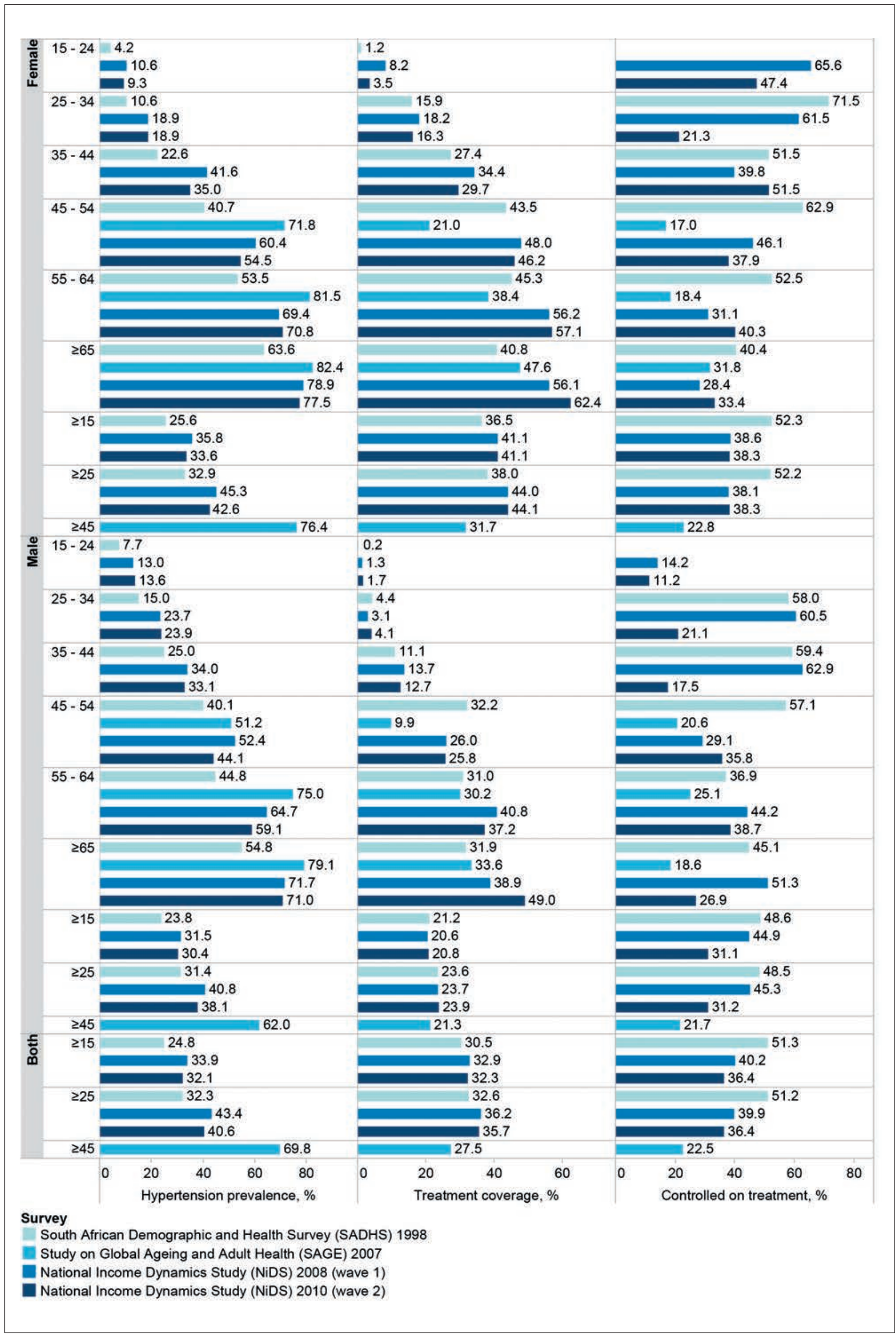

Fig. 3. Hypertension indicators based on four surveys, by gender and age group, 1998 - 2010. 
Table 2. Main chronic NCD indicators in the DHIS, SA

\begin{tabular}{|c|c|c|c|c|c|c|c|}
\hline \multirow[b]{2}{*}{ Group } & \multirow[b]{2}{*}{ Indicator } & \multicolumn{5}{|c|}{ Existing data based on NIDS 2010} & \multirow[b]{2}{*}{ Status of indicator in NIDS 2013} \\
\hline & & 2008/09 & $2009 / 10$ & 2010/11 & 2011/12 & $2012 / 13$ & \\
\hline \multirow[t]{10}{*}{ Chronic care } & Asthma detection rate, $\%$ & & & 0.1 & 0.2 & 0.1 & Discontinued \\
\hline & Asthma $<18$ years rate, $\%$ & & & 15.5 & 16.9 & 18.2 & Discontinued \\
\hline & $\begin{array}{l}\text { Diabetes high-risk cases incidence } \\
\text { rate (annualised), /1 } 000\end{array}$ & & & 2.3 & 2.8 & 1.8 & $\begin{array}{l}\text { NIDS } 2013 \text { - changed to 'Diabetes } \\
\text { incidence (annualised)' }\end{array}$ \\
\hline & Diabetes mellitus caseload, \% & 3.1 & 3.2 & 2.5 & 1.7 & 1.3 & Discontinued \\
\hline & Diabetes mellitus detection rate, $\%$ & 0.1 & 0.1 & 0.1 & 0.1 & 0.1 & $\begin{array}{l}\text { NIDS } 2013 \text { (split into }<18 \text { and } \\
\geq 18 \text { years) and changed to } / 1000\end{array}$ \\
\hline & Epilepsy detection rate, $\%$ & & & 0.1 & 0.1 & 0.1 & Discontinued \\
\hline & Epilepsy < 18 years rate, $\%$ & & & 18.0 & 17.2 & 17.2 & Discontinued \\
\hline & Hypertension caseload, \% & 12.1 & 12.3 & 9.0 & 6.4 & 5.1 & Discontinued \\
\hline & Hypertension detection rate, $\%$ & 0.3 & 0.3 & 0.4 & 0.3 & 0.2 & Discontinued \\
\hline & $\begin{array}{l}\text { Hypertension high-risk cases } \\
\text { incidence rate (annualised), / } 1000\end{array}$ & & & 7.6 & 7.6 & 4.9 & $\begin{array}{l}\text { NIDS } 2013 \text { - changed to } \\
\text { 'Hypertension incidence } \\
\text { (annualised)'* }\end{array}$ \\
\hline Eye care & $\begin{array}{l}\text { Cataract surgery rate } \\
\text { (annualised), /million }\end{array}$ & 231.5 & 387.6 & 546.9 & 729.8 & 553.2 & NIDS 2013 \\
\hline \multirow[t]{2}{*}{ Mental health } & Mental health caseload, \% & 0.3 & 0.3 & 0.9 & 1.3 & 1.4 & $\begin{array}{l}\text { NIDS } 2013 \text { - additional indicators } \\
\text { added relating to mental health } \\
\text { admissions }\end{array}$ \\
\hline & $\begin{array}{l}\text { Mental health visits } \geq 18 \text { years } \\
\text { rate, \% }\end{array}$ & 94.7 & 94.0 & 94.8 & 95.7 & 95.6 & NIDS 2013 \\
\hline $\begin{array}{l}\text { Reproductive } \\
\text { health }\end{array}$ & $\begin{array}{l}\text { Cervical cancer screening } \\
\text { coverage (annualised), \% }\end{array}$ & 46.5 & 47.6 & 52.2 & 55.0 & 55.4 & NIDS 2013 \\
\hline
\end{tabular}

hypertensive disease (Fig. 2), although the overall age-standardised mortality for NCDs in Mangaung (1 082.2/100 000 population) is 1.6 times higher than in Cape Town (676.0).

Extensive routine information systems exist for key infectious diseases as well as maternal and child health, but minimal information is available on NCDs. Chronic disease rates collected by the District Health Information System (DHIS) are difficult to interpret in terms of disease burden or service coverage. ${ }^{[1]}$ Many indicators are not collected by all provinces, and most indicators have either been discontinued or altered between the 2010 and 2013 National Indicator Data Sets. Table 2 shows the currently available chronic disease indicators at national level.

Fig. 3 shows hypertension indicators based on four surveys: SADHS, SAGE, NiDS 2008 and NiDS 2010. The number of survey respondents (aged $\geq 15$ years) was 13826 for SADHS 1998, 4227 for SAGE 2007, 16878 for NiDS 2008 and 21955 for NiDS 2010. National household surveys showed a measured hypertension prevalence of over $40 \%$ in adults aged $\geq 25$ years in 2010. Selfreported prevalence was much lower, indicating that most cases were not diagnosed. Treatment coverage was very low $(35.7 \%)$, and only $36.4 \%$ of those on treatment were controlled. Results show that the prevalence of hypertension has increased since 1998, and that it increases with advancing age (both genders, all surveys), with high levels of hypertension (typically between 50\% and 75\%) among individuals aged $\geq 45$ years in all surveys. In general, the prevalence among young males is higher than that among young females, while it is higher among females in the older age categories. The SAGE 2007 generally reports higher prevalences than the NiDS 2008 per gender and age category. In an analysis of the SAGE data for all six countries, SA had the highest hypertension prevalence rate of $77.9 \%$ in people aged $\geq 50$ years. ${ }^{[12]}$

Fig. 4 outlines the number of adults with hypertension, the number on treatment and the number controlled on treatment based on the three most recent surveys. There are about 8.2 million people aged $\geq 15$ years with hypertension in SA, of whom about 2.7 million are on treatment (and about 0.9 million controlled on treatment). The estimated diagnosed cases of hypertension reported in the South African Health Review 2011 (based on the total population and disease incidence rates extrapolated from the private sector risk equalisation fund study) was 3.3 million (with 2.1 million on treatment). ${ }^{[13]}$ Similarly, the Statistics SA General Household Survey 2010 indicates that 3.2 million adults aged $\geq 25$ years have selfreported hypertension. ${ }^{[14]}$ Multiple sources therefore confirm the huge number of people with hypertension who are not diagnosed and hence are untreated, and the substantial number on treatment who are not controlled.

\section{Discussion}

Burden of disease analysis is useful for monitoring the ultimate impact of NCDs. In 2009, YLLs due to NCDs surpassed those from communicable and related causes. NCDs such as cerebrovascular, hypertensive and ischaemic heart disease are in the leading ten agestandardised causes of death in all metros. Improved quality and completeness of death registration are needed for reliable results. 


\begin{tabular}{|c|c|c|c|c|}
\hline$\frac{0}{\pi}$ & $15-24$ & 403490 & 32978 & 21347 \\
\hline$\tilde{\Xi}$ & & - 349465 & 12171 & 5082 \\
\hline & $25-34$ & 621717 & | 113157 & 64282 \\
\hline & & 口 636695 & | 103846 & 21319 \\
\hline & $35-44$ & 1009547 & 346855 & | 131201 \\
\hline & & 869689 & | 258360 & | 119101 \\
\hline & $45-54$ & 2494214 & 523882 & 88713 \\
\hline & & 1154939 & 554504 & | 225471 \\
\hline & & 1002033 & - 462734 & I 164017 \\
\hline & $55-64$ & 1146194 & 440406 & 80014 \\
\hline & & 908080 & 510120 & | 133474 \\
\hline & & 950085 & a 542722 & I 195390 \\
\hline & $\geq 65$ & 1189139 & 566242 & | 176094 \\
\hline & & 839248 & 471214 & | 113143 \\
\hline & & 864124 & 539495 & | 150710 \\
\hline & $\geq 15$ & 4937020 & 2028827 & 688917 \\
\hline & & 4672090 & 1919329 & 655618 \\
\hline & $\geq 25$ & 4533531 & 1995849 & 667570 \\
\hline & & 4322625 & 1907158 & - 650537 \\
\hline & $\geq 45$ & 4829547 & 1530530 & 344820 \\
\hline \multirow[t]{19}{*}{$\frac{0}{\frac{0}{\pi}}$} & $15-24$ & $\begin{array}{r}454030 \\
\square 500834\end{array}$ & $\begin{array}{l}6091 \\
8495\end{array}$ & $\begin{array}{l}863 \\
634\end{array}$ \\
\hline & $25-34$ & 612574 & 19290 & 10341 \\
\hline & & 703080 & 28623 & 6043 \\
\hline & $35-44$ & 566148 & 177652 & 39987 \\
\hline & & 663838 & | 84599 & 13903 \\
\hline & $45-54$ & 1566783 & | 154661 & 31794 \\
\hline & & $=642445$ & | 166778 & 37502 \\
\hline & & ㅁ 608362 & | 156732 & 51323 \\
\hline & $55-64$ & 979181 & 295760 & 68596 \\
\hline & & 558435 & I 228073 & 88038 \\
\hline & & - 589746 & I 219442 & 179089 \\
\hline & $\geq 65$ & 749094 & 251564 & 45901 \\
\hline & & 474743 & | 184901 & 77801 \\
\hline & & 489658 & I 240014 & 48713 \\
\hline & $\geq 15$ & 3308376 & 682784 & | 254531 \\
\hline & & 3555518 & - 737905 & I 199706 \\
\hline & $\geq 25$ & 2854346 & 676693 & | 253668 \\
\hline & & 3054684 & 729410 & I 199072 \\
\hline & $\geq 45$ & 3295057 & 701984 & 146291 \\
\hline \multirow{7}{*}{ ક્ڤ } & $\geq 15$ & 8245396 & 2711611 & 943448 \\
\hline & & 8227608 & 2657234 & - 855324 \\
\hline & $\geq 25$ & 7387877 & 2672542 & 921239 \\
\hline & & $\mathbf{7} 3377309$ & 2636568 & 849609 \\
\hline & $\geq 45$ & 8124604 & 2232514 & 491111 \\
\hline & & $\begin{array}{llllll}0 M & 2 M & 4 M & 6 M & 8 M & 10 M\end{array}$ & 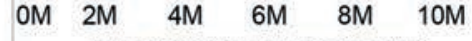 & $0 M \quad 2 M \quad 4 M \quad 6 M$ \\
\hline & & With hypertension, $n$ & Hypertensives on treatment, $n$ & Treated hypertensives controlled, $n$ \\
\hline \multicolumn{5}{|c|}{$\begin{array}{l}\text { Survey } \\
\text { Study on Global Ageing and Adult Health (SAGE) } 2007 \\
\text { National Income Dynamics Study (NiDS) } 2008 \text { (wave 1) } \\
\text { National Income Dynamics Study (NiDS) } 2010 \text { (wave 2) }\end{array}$} \\
\hline
\end{tabular}

Fig. 4. Estimated numbers with hypertension, on treatment and controlled on treatment, based on three surveys, by gender and age group, 2007 - 2010. $(M=$ million.$)$

The DHIS has potential to monitor health service delivery for NCDs, but late adoption of well-formulated indicators has limited its utility so far.

Surveys provide limited geographical disaggregation and trend analysis, yet they address some monitoring gaps and are better suited to understanding the complex interplay of risk factors, demographics, equity, service availability and quality that are components of achieving UHC. The South African National Health and Nutrition Examination Survey ${ }^{[15]}$ is expected to provide rich data for evaluation of NCDs. The reported prevalence of hypertension of $10.2 \%$ for participants aged $\geq 15$ years is substantially lower than expected, but cannot be directly compared with other sources because it only measures high blood pressure (systolic $\geq 140 \mathrm{mmHg}$ and diastolic $\geq 90$ $\mathrm{mmHg}$ ) and excludes patients on medication and controlled. There is a need to standardise the definition of hypertension indicators in terms of the age categories included (World Health Organization $\geq 18$ years, SA not specified but $\geq 15$ years usually reported) and whether controlled hypertensives are included (hypertension prevalence) or not (raised systolic and/or diastolic pressure prevalence), so as to ensure uniformity across all current monitoring frameworks.

More work is needed to refine NCD monitoring in SA, to enable the ten goals of the National Strategic Plan to be assessed. The priority 
targets for NCDs need to be integrated into national health planning processes, and surveillance requires integration into national health information systems. Finally, a greater focus on integrated chronic care within primary healthcare is needed at all levels to meet the longterm requirements for the effective management of NCDs.

\section{References}

1. World Health Organization. Health Systems Financing: The Path to Universal Coverage. The World Health Report 2010. Geneva: WHO, 2010. wwww.who.int/ $/$ hr $/ 2010 /$ en/ (accessed 22 November 2010).
2. Thematic Group on Health for All. Health in the Framework of Sustainable Development. Technical Report 2. Thematic Group on Health for All. Health in the Framework of Sustainable Development. Technical Report
for the Post-2015 Development Agenda. Paris: Sustainable Development Solutions Network (SDSN), 2014. for the Post-2015 Development Agenda. Paris: Sustainable Development Solutions Network (SDSN), 2014. 3. World Health Organization. Draft Comprehensive Global Monitoring Framework and Targets for the
Prevention and Control of Noncommunicable Diseases A66/8. Geneva: WHO, 2013. http://apps.who. Prevention and Control of Noncommunicable Diseases A66/8. Geneva: WHO, 2013. http://apps.who int/gb/ebwha/pdf_files/WHA66/A66_8-en.pdf (accessed 8 May 2013)

4. National Department of Health. Strategic Plan for the Prevention and Control of Non-Communicable Diseases 2013-17. Pretoria: NDoH, 2013

5. Abegunde DO, Mathers CD, Adam T, Ortegon M, Strong K. The burden and costs of chronic disease in low-income and middle-income countries. Lancet 2007;370(9603):1929-1938. [http://dx.do org/10.1016/S0140-6736(07)61696-1]
6. Mayosi BM, Flisher AJ, Lalloo UG, Sitas F, Tollman SM, Bradshaw D. The burden of non-communicable diseases in South Africa Lancet 2009;374(9693):934-947. [http.//dx doi.org/10.1016/S0140-6736(09)61087-4] Department of Health, Medical Research Council, and Macro International. South African Demographic and Health Survey 1998. Full Report. Pretoria: National Department of Health, 2002. . Kowal P, Chatterii S, Naidoo N, et al. Data resource profile: The World Health Organization Study on globa AGEing and adult health (SAGE). Int J Epidemiol 2012;41(6):1639-1649. [http://dx.doi.org/ 10.1093/ije/dys210] 9. Southern Africa Labour and Development Research Unit. National Income Dynamics Study 2008, Wave 1 [dataset]. Version 4.1 ed. Cape Town: DataFirst, 2012

10. Southern Africa Labour and Development Research Unit. National Income Dynamics Study 2010-11, Wave 2 [dataset]. Version 1 ed. Cape Town: DataFirst, 2012.

11. Massyn N, Day C, Haynes R, Barron P, English R, Padarath A. District Health Barometer 2011/12. Durban: Health Systems Trust, 2013

12. Lloyd-Sherlock P, Beard J, Minicuci N, Ebrahim S, Chatterii S. Hypertension among older adults in low- and middle-income countries: Prevalence, awareness and control. Int J Epidemiol 2014;43(1):11628. [http://dx.doi.org/10.1093/ije/dyt215]

13. Day C, Gray A, Budgell E. Health and related indicators. In: Padarath A, English R, eds. South African Health Review 2011. Durban: Health Systems Trust, 2011

14. General Household Survey 2010. Statistical Release P0318 (Revised version). Pretoria: Statistics South Africa, 2011.

15. Shisana O, Labadarios D, Rehle T, et al. South African National Health and Nutrition Examination Survey (SANHANES-1). Cape Town: HSRC Press, 2013

Accepted 2 April 2014 